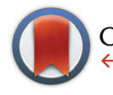

CrossMark

\&lick for updates

Cite this: Analyst, 2016, 141, 1233

Received 1st December 2015, Accepted 13th January 2016

DOI: $10.1039 / c 5 a n 02469 b$

www.rsc.org/analyst

\section{Utilising copper screen-printed electrodes (CuSPE) for the electroanalytical sensing of sulfide $\uparrow$}

\author{
Bhawana Thakur, ${ }^{\mathrm{a}, \mathrm{b}}$ Elena Bernalte, ${ }^{\mathrm{b}, \mathrm{c}}$ Jamie P. Smith, ${ }^{\mathrm{b}}$ Christopher W. Foster, ${ }^{\mathrm{b}}$ \\ Patricia E. Linton, ${ }^{d}$ Shilpa N. Sawant ${ }^{a}$ and Craig E. Banks*b
}

\begin{abstract}
A mediatorless sulfide electrochemical sensing platform utilising a novel nanocopper-oxide screen-printed electrodes (CUSPE) is reported for the first time. The state-of-the-art screen-printed electrochemical sensors demonstrate their capability to quantify sulfide within both the presence and absence of an array of interferents with good levels of sensitivity and repeatability. The direct sensing (using linear sweep voltammetry) of sulfide utilising the CuSPEs provides a mediatorless approach for the detection of sulfide, yielding useful analytical signatures that can be successfully quantified. The proposed novel protocol using the CuSPEs is successfully applied to the sensing of sulfide within drinking water exhibiting a high level of recovery.
\end{abstract}

\section{Introduction}

Monitoring the levels of sulfide is extremely important from both an environmental and a medical diagnostic point of view; apart from being a common by-product of various industrial processes, sulfide in low concentrations plays a very important role in mammalian physiological processes such as cellular signalling and redox biology. ${ }^{1}$ For example, high concentrations of hydrogen sulfide $\left(\mathrm{H}_{2} \mathrm{~S}\right)$ are reported to have a toxic effect upon human health ${ }^{2}$ while within the human body, anomalies in the concentration of $\mathrm{H}_{2} \mathrm{~S}$ can act as a marker for

\footnotetext{
${ }^{a}$ Chemistry Division, Bhabha Atomic Research Centre, Mumbai 400085, India

${ }^{b}$ Faculty of Science and Engineering, School of Science and the Environment, Division of Chemistry and Environmental Science, Manchester Metropolitan University, Chester Street, Manchester M1 5GD, UK.E-mail: c.banks@mmu.ac.uk; http://www. craigbanksresearch.com; Fax: +44 (0)161-247-6831; Tel: +44 (0)161-247-1196 ${ }^{c}$ Departamento de Quimica Analitica, Facultad de Ciencias, Universidad de Extremadura, Avda. de Elvas s/n, 06006 Badajoz, Spain

${ }^{d}$ Faculty of Science and Engineering, School of Science \& the Environment, Division of Biology and Conservation Ecology, Manchester Metropolitan University, Chester Street, Manchester M1 5GD, UK

$\dagger$ Electronic supplementary information (ESI) available. See DOI: 10.1039/ c5an02469b
}

some diseases. For instance, a low concentration of $\mathrm{H}_{2} \mathrm{~S}$ can be an indicator of Alzheimer's and Parkinson's diseases, whereas a high concentration of $\mathrm{H}_{2} \mathrm{~S}$ is typically an indicator of Down's syndrome and type 1 diabetes. $^{3}$ Furthermore, sulfide is one of the most common by-products released via sulfate reducing bacteria which thrive in swamps, stale protein-rich food (composed of sulfur-containing amino acids) and hot water springs. ${ }^{4}$ All the aforementioned factors demand the need for low-cost, rapid and highly sensitive detection methods for sulfide.

Electrochemical sensors are a cost effective alternative for the detection of target analytes, ${ }^{5-8}$ offering an efficient technique with improved scope for clinical assays and environmental applications whilst also having a high efficacy compared to other conventional techniques such as fluorescence, ${ }^{4}$ gas chromatography, ${ }^{9}$ chemiluminiscence, ${ }^{10}$ ICP-AES ${ }^{11}$ or mass spectrometry. ${ }^{12}$ Metallic nanoparticles and semiconductor-based electrodes have been reported for the direct sensing of $\mathrm{H}_{2} \mathrm{~S}$ gas. ${ }^{13-17}$ Such metals are often expected to have increased catalytic effects for the electrochemical oxidation of sulfide. ${ }^{18,19}$ However, until now, there are very limited reports of using metallic based electrodes such as platinum, gold and nickel electrodes for the direct sensing of sulfide within aqueous media; ${ }^{18,20}$ Table 1 provides an overview. Owing to the excellent affinity towards sulfide in comparison to various other metals, copper is extensively used in construction of optical and semiconductor based sulfide sensors. ${ }^{13,14,16,21,22}$ Although perhaps surprisingly, there are no reports of sensors based solely on copper electrodes for the electrochemical sensing of sulfide in aqueous media.

Screen-printed electrodes (SPEs) have added a new dimension to the field of electroanalysis due to their commendable properties, which make them highly suitable for point-of-care diagnostics. ${ }^{6,23-29}$ Screen-printing technology has emerged as a very promising alternative for the fabrication of low cost, highly reproducible one-shot sensors. ${ }^{30,31}$ SPEs also overcome the additional step of mechanical polishing which is routinely 
Table 1 A brief overview of metallic-based electrochemical sensors for the detection of sulfide in aqueous media

\begin{tabular}{|c|c|c|c|c|c|c|}
\hline Electrode material & Methodology & $\begin{array}{l}\text { Sensitivity } \\
\mu \mathrm{A} \mu \mathrm{M}^{-1} \mathrm{~cm}^{-2}\end{array}$ & $\begin{array}{l}\text { LOD } \\
\mu \mathrm{M}\end{array}$ & $\begin{array}{l}\text { Linear } \\
\text { range } \mu \mathrm{M}\end{array}$ & Comments & Ref. \\
\hline $\begin{array}{l}\text { Pt } \\
\text { Gold }\end{array}$ & $\mathrm{CV}$ & $\begin{array}{l}9.9 \times 10^{-8} \\
1.8 \times 10^{-6}\end{array}$ & $\begin{array}{r}122.0 \\
5.0\end{array}$ & $\begin{array}{l}200-800 \\
25-50\end{array}$ & pH 10 Borax buffer & 46 \\
\hline $\begin{array}{l}\text { Electrochemically generated nickel } \\
\text { oxide layer at GCE and SPE }\end{array}$ & $\mathrm{CV}$ & $\begin{array}{l}5.57 \times 10^{-3} \\
3.18 \times 10^{-3}\end{array}$ & 20.0 & $\begin{array}{l}20-90 \\
20-80\end{array}$ & $\begin{array}{l}\text { In situ analysis in pH } 4 \text { acetate } \\
\text { buffer. Deposition time } 180 \mathrm{~s}\end{array}$ & 47 \\
\hline $\begin{array}{l}\text { Nickel hydroxide: macroelectrodes } \\
\text { and microelectrodes }\end{array}$ & $\mathrm{CV}$ & $\gamma$ & $\begin{array}{l}19.0 \\
10.0\end{array}$ & $\begin{array}{l}20-200 \\
20-200\end{array}$ & $\begin{array}{l}\text { Detection in alkaline media. } \\
\text { Deposition time } 300 \mathrm{~s}\end{array}$ & 20 \\
\hline Indium Tin Oxide (ITO) & $\mathrm{CV}$ & $\gamma$ & 8.0 & $50-350$ & $0.1 \mathrm{M} \mathrm{KNO}_{3}$ aq. & 48 \\
\hline CuSPEs & LSV & $2.83 \times 10^{-3}$ & 41.0 & $50-1000$ & $\begin{array}{l}\text { Neutral media ( } \mathrm{pH} 7 \mathrm{~B}-\mathrm{R} \text { buffer). } \\
\text { Deposition time } 60 \mathrm{~s}\end{array}$ & This work \\
\hline
\end{tabular}

Pt: platinum electrode; GCE: glassy carbon electrode, SPE: screen-printed carbon electrode, CV: cyclic voltammetry, LSV: linear sweep voltammetry, LOD: limit of detection, $\gamma$ : value not reported.

used in the case of solid electrodes to remove the adsorbed species to avoid any fouling of the electrode. Moreover, using SPEs for the direct oxidation of sulfide can be potentially advantageous because sensing can be achieved without the use of a mediator or modification with redox active polymers or metal composites.

In this work, a mediatorless sulfide sensing platform based upon a novel nanocopper-oxide SPE (CuSPE) is reported for the first time. Although copper and copper nanoparticles based SPEs (electrochemically deposited thus requiring a prestep prior to use) have been reported for various analytes, ${ }^{32-35,36}$ the present paper is the first documented work on use of a nanocopper oxide screen-printed electrodes for direct sensing of sulfide which provides a novel electrochemical sensing platform that requires no pre-treatment or prior preparatory step.

\section{Experimental}

All chemicals were of highest analytical grade (Sigma Aldrich) and used as received. All the solutions were prepared with deionised water of resistivity $18.2 \mathrm{M} \Omega \mathrm{cm}$. Phosphate buffer solution (PBS) of $\mathrm{pH} 7$ were made with disodium hydrogen phosphate $(0.025 \mathrm{M})$ and potassium dihydrogen phosphate $(0.025 \mathrm{M})$. For the solution of $\mathrm{pH} 2.5$ to 11, Britton-Robinson buffer (B-R buffer) comprising of $0.04 \mathrm{M}$ each of acetic, phosphoric and boric acids was adjusted to the desired $\mathrm{pH}$ by adding $0.2 \mathrm{M} \mathrm{NaOH}$. Stock sulfide solutions $(0.05 \mathrm{M})$ were prepared from sodium sulfide using degassed PBS and used within $4 \mathrm{~h}$ to minimise concentration losses due to aerial oxidation. ${ }^{18}$ Water samples were collected from a drinking water tap after running for one minute, diluted with PBS $(1: 1, \mathrm{pH}$ 7), stored at room temperature and used within a day of sampling.
Voltammetric measurements were carried out using an EmStat $^{3}$ potentiostat and controlled by PS Trace 4.4 software. All the electrochemical measurements were carried out using screen-printed electrodes (SPEs) consisted of copper working electrodes ( $3 \mathrm{~mm}$ diameter), a graphitic counter electrode and a $\mathrm{Ag} / \mathrm{AgCl}$ pseudo reference electrode. Linear sweep voltammetry (LSV) experiments were performed either in Britton-Robinson (B-R buffer) ( $\mathrm{pH} 2.5$ to $\mathrm{pH}$ 11) or phosphate buffer solution (PBS) (pH 7) applying deposition time and potential of $60 \mathrm{~s}$ and $-0.4 \mathrm{~V}$ respectively. Scanning electron microscope (SEM) images and surface element analysis were obtained with a JEOL JSM-5600LV model equipped with an energy-dispersive X-ray (EDX) microanalysis package.

The novel CuSPEs ( $3 \mathrm{~mm}$ working electrode diameter) were fabricated in-house utilising appropriate stencil designs using a microDEK1760RS screen-printing machine (DEK, Weymouth, UK). A carbon-graphite ink formulation (Product Code: C2000802P2; Gwent Electronic Materials Ltd, UK) was first screen-printed onto a polyester flexible film (Autostat, 250 micron thickness). ${ }^{37,38}$ This layer was cured in a fan oven at 60 degrees for 30 minutes. Next a silver/silver chloride reference electrode was included by screen-printing $\mathrm{Ag} / \mathrm{AgCl}$ paste (Product Code: C2040308P2; Gwent Electronic Materials Ltd, UK) onto the polyester substrate. A dielectric paste/ink (Product Code: D2070423D5; Gwent Electronic Materials Ltd, UK) was next printed to cover the connection and define the carbon-graphite working electrode ( $3 \mathrm{~mm}$ diameter). For the creation of the CuSPE the addition of a commercially available nanocopper-based ink (Product Code: C2110127D3; Gwent Electronic Materials Ltd, UK) was finally printed over the carbon-graphite working electrode, presenting a uniform surface. After curing at 60 degrees for 30 minutes the screenprinted electrode is ready to use, after curing the electrodes were connected via an edge connector to ensure a secure electrical connection. ${ }^{39}$ 


\section{Results and discussion}

The nanocopper-oxide screen-printed electrodes were fabricated as described with in the Experimental section. An optical image of a typical CuSPE is presented within ESI Fig. $1 \dagger$ where the CuSPE is fabricated via screen-printing a commercial available nanocopper ink upon a flexible polyester substrate with the sensor comprising a graphite counter and a $\mathrm{Ag} / \mathrm{AgCl}$ pseudo reference electrode. Closer inspection of the working electrode was obtained using Scanning Electron Microscopy (SEM) which was performed upon the underlying graphitic-SPE before and after screen-printing with the nanocopper ink. ESI Fig. $2 \mathrm{~A}$ and $\mathrm{B} \uparrow$ show the unmodified graphitic surface which is consistent with our prior literature reports. $^{40,41}$ The fabrication of the copper nanoparticulate SPEs as described in the Experimental section produces a relatively rough, porous and uniform surface which is clearly observed in ESI Fig. 2C-F. $\uparrow$ Complementary Energy Dispersive X-ray Spectroscopy analysis (EDX) confirms the SPE surface comprises nanocopper/nanocopper oxide (ESI Fig. $3 \dagger$ ).

Next, the voltammetric behaviour of $1 \mathrm{mM}$ sulfide was explored. Linear sweep voltammetry (LSV) was performed in pH 8 B-R buffer solution utilising CuSPEs (Fig. 1), where it is clearly observed that the CuSPE exhibits a large voltammetric signature. This useful electroanalytical signal is likely the result of the formation of a copper sulfide layer, which strips off at anodic potentials (eqn (1a) and (1b)) giving rise to a large voltammetric peak current/analytical signal. An important observation upon the utilisation of the CuSPEs is that an oxidation peak for sulfide only occurs when the copper particles upon the surface of the SPE have been displaced (within the solution) during agitation. This behaviour is similar to the study reported by Giovanelli et $a{ }^{18}{ }^{18}$ reported for the determination of sulfide at pre-oxidised nickel electrodes, wherein the

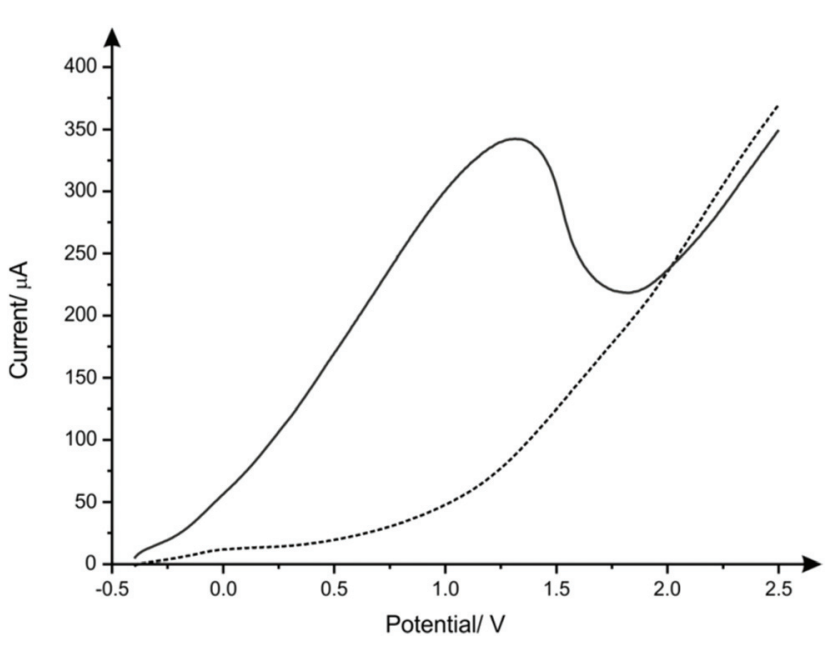

Fig. 1 Linear sweep voltammograms using CuSPEs in the absence (dashed line) and presence of $1 \mathrm{mM}$ sulfide (solid line) in $\mathrm{pH} 8 \mathrm{~B}-\mathrm{R}$ buffer solution. Deposition time and potential of $60 \mathrm{~s}$ at $-0.4 \mathrm{~V}$ respectively (vs. $\mathrm{Ag} / \mathrm{AgCl}$ ) and scan rate $100 \mathrm{mV} \mathrm{s}^{-1}$. sensing mechanism involved dissolution of nickel electrode in acetate buffer followed by the formation and stripping of a nickel sulfide layer on the surface of electrode. There are also redox reactions previously reported in literature that take place in parallel when copper comes in contact with sulfide (eqn (2a) and (2b)). ${ }^{42,43}$ Although there is just one oxidation peak observed in the LSV of CuSPE in the presence of $1 \mathrm{mM}$ sulfide, the reactions mentioned above could possibly contribute to the peak current, thereby increasing the overall current.

$$
\begin{gathered}
\mathrm{CuO}+\mathrm{HS}^{-} \rightleftarrows \mathrm{CuS}+\mathrm{OH}^{-} \\
\mathrm{CuS} \rightleftarrows \mathrm{Cu}^{2+}+\mathrm{S}+2 \mathrm{e}^{-} \\
2 \mathrm{Cu}+\mathrm{HS}^{-}+\mathrm{OH}^{-} \rightleftarrows \mathrm{Cu}_{2} \mathrm{~S}+\mathrm{H}_{2} \mathrm{O}+2 \mathrm{e}^{-} \\
\mathrm{Cu}_{2} \mathrm{~S}+2 x \mathrm{OH}^{-} \rightleftarrows \mathrm{Cu}_{2-x} \mathrm{~S}+x \mathrm{CuO}+x \mathrm{H}_{2} \mathrm{O}+x \mathrm{e}^{-}
\end{gathered}
$$

Note that to ensure electrode reproducibility a protocol in the form of a deposition time at a suitable potential was found to be required. Through trial and error the largest and most reproducible electrochemical response was observed when the deposition time and potential were chosen to be 60 seconds and $-0.4 \mathrm{~V}$; this electrochemical protocol was used herein. It is likely that there is disruption of the nanocopper-oxide layer by the initiation of the electrochemical sweep in the presence of sulfide. This electrochemical protocols then aid in the facilitation and formation of CuS at the electrode surface (see eqn (1) and (2)) which helps ensure an optimal electroanalytical signal for sensing of sulfide. This is similar to that reported by Giovanelli et $a .^{18}$ for the case of nickel oxide modified electrodes.

To optimise the solution composition for the electrochemical oxidation of sulfide, the voltammetric response of CuSPEs was recorded in the presence of $1 \mathrm{mM}$ sulfide within a range of pHs. As is represented in ESI Fig. $4, \dagger$ the observed voltammetry shows a negative shift in peak potential and a considerable decrease within the peak current upon the increase of the solution $\mathrm{pH}$. The high current at lower pHs can be attributed to the fast electron kinetics of copper within an acidic media. Additionally, at alkaline pHs the formation of a thick layer of copper oxide film can passivate the CuSPE and thus decrease the peak current. ${ }^{44}$ As such, to make this electrochemical system more feasible for practical applications, e.g. environmental and biological settings, $\mathrm{pH} 7$ was selected in subsequent experiments given it still maintains a satisfactory level of sensitivity. Further note the following $\mathrm{p} K_{\mathrm{a}}$ values: $\mathrm{HS}^{-} \rightarrow \mathrm{H}^{+}$ $+\mathrm{S}^{2-} ; \mathrm{p} K_{\mathrm{a}}=14.15 ; \mathrm{H}_{2} \mathrm{~S} \rightarrow \mathrm{H}^{+}+\mathrm{HS}^{-} ; \mathrm{p} K_{\mathrm{a}}=6.88$. Thus according at this $\mathrm{pH}$ the dominant species is the singly protonated $\mathrm{HS}^{-}$ ion which agrees with the mechanism presented in eqn (1) and (2).

The electroanalytical performance of CuSPEs towards the detection of sulfide was next evaluated. A calibration curve was constructed using LSV and a single CuSPE over the entire concentration range $(0.0$ to $1.0 \mathrm{mM})$ in a $\mathrm{pH} 7$ phosphate buffer solution. As expected, there was an increase of the peak current upon increasing the concentration of sulfide (Fig. 2A). The corresponding calibration plot (Fig. 2B) demonstrates a 

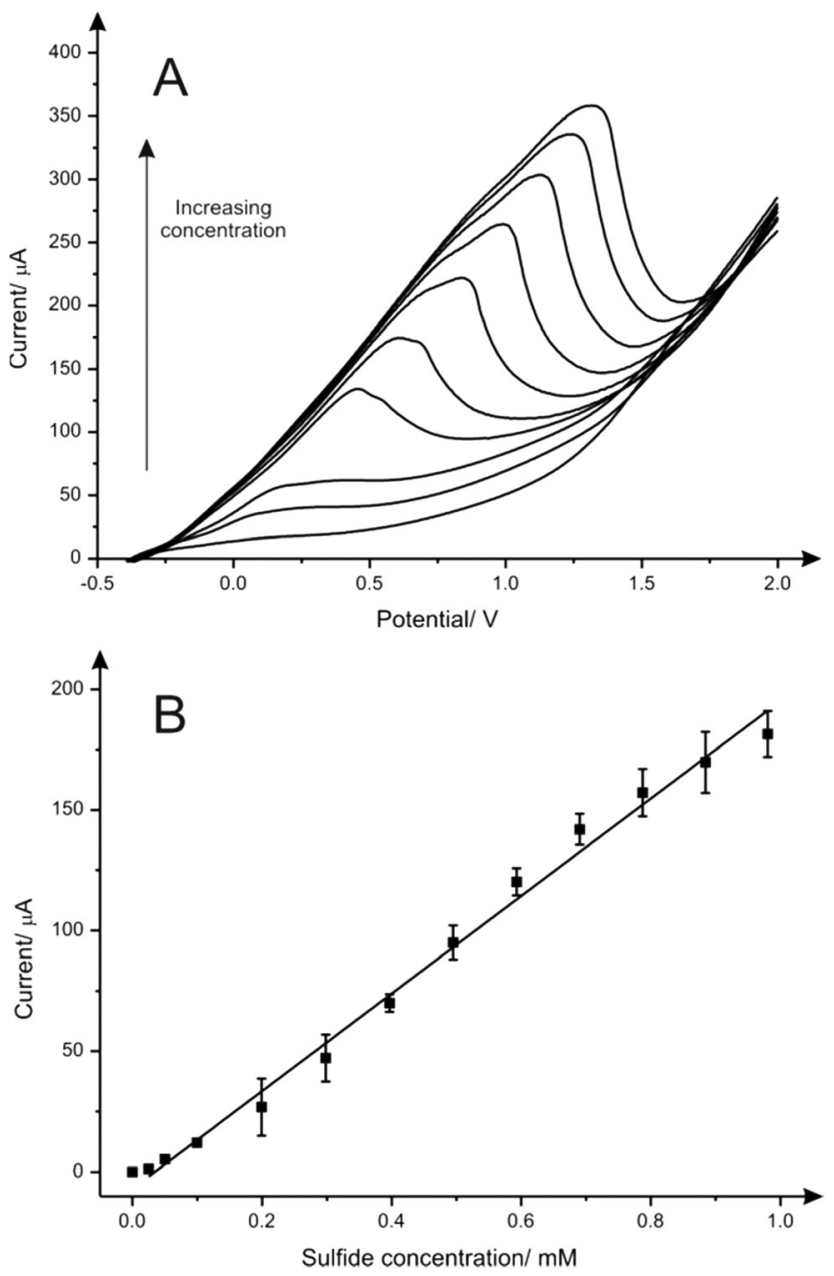

Fig. 2 (A) LSV of a CUSPE towards increasing concentration of sulfide over a range of 0.0 to $0.1 \mathrm{mM}$ at $\mathrm{pH} 7 \mathrm{PBS}$. Deposition time and potential of $60 \mathrm{~s}$ at $-0.4 \mathrm{~V}$ respectively $(\mathrm{vs}$. $\mathrm{Ag} / \mathrm{AgCl})$, scan rate $100 \mathrm{mV} \mathrm{s}^{-1}$ applied between each addition. (B) The corresponding calibration plot $(N=3)$.

linear response $\left(I / \mu \mathrm{A}=202.04 \mu \mathrm{A}\left[\mathrm{mM}^{-1}\right]-6.89 \mu \mathrm{A} ; R^{2}=0.992\right.$; $N=3)$ over the analytical range studied (0.0 to $1.0 \mathrm{mM})$ and a very high sensitivity $\left(2832.3 \mu \mathrm{A} \mathrm{mM} \mathrm{m}^{-1} \mathrm{~cm}^{-2}\right)$ alongside a limit of detection $(3 \sigma)$ of $41.0 \mu \mathrm{M}$. Analytical suitability for sulfide determination in aqueous media using the CuSPEs is demonstrated comparing the results obtained with the data reported in the literature from different metallic-based electrodes, as shown in Table 1. In terms of sensitivity, CuSPEs show an acceptable LOD value considering the low deposition potential applied within the methodology proposed and its feasibility for the sulfide determination in neutral media which make it more appropriate for in situ environmental and point-of-care applications.

Additionally, to evaluate the reliability of the proposed methodology, interference tests were performed in the presence of various anions, cations and organic compounds which are likely to be present with sulfide within real samples. ${ }^{45}$ Interference from chloride, nitrate, nitrite, carbonate, sulfite, thiosulfate, citrate and acetate were tested by spiking an aqueous solution (PBS pH 7) with $2 \mathrm{mM}$ of the corresponding sodium salts within the presence of $0.1 \mathrm{mM}$ sulfide. For the cations, copper, nickel, magnesium, cobalt, lead and ammonium buffer solution was spiked with $2 \mathrm{mM}$ of their corresponding nitrate or chloride salts in the absence of sulfide to avoid formation of insoluble metal sulfides. ${ }^{2,45}$ Apart from these anions and cations, the effect of organic compounds thiamine, riboflavin, urea and ascorbic acid were also studied. As illustrated in Fig. 3, significant interferences were observed with sulfite, nitrite, thiosulfate, acetate, citrate and urea having an inhibitory effect upon the current of the sulfide oxidation peak. This could be potentially avoided by coupling CuSPEs with sulfide selective membranes and/or electrochemically inert anion complexing agents. Additionally, no interferences were reported to cations mentioned above.

The proposed analytical protocol utilising LSV with CuSPEs was successfully applied to determine sulfide concentration in real tap water samples. For this purpose, apparent recovery studies were carried out within tap water (spiked with known concentrations of sulfide) and the results attained are shown in Table 2. The RSD values following testing are shown to be no more than $\pm 3 \%(N=3)$ and indicate suitability of CuSPE for the monitoring of sulfide in real samples.

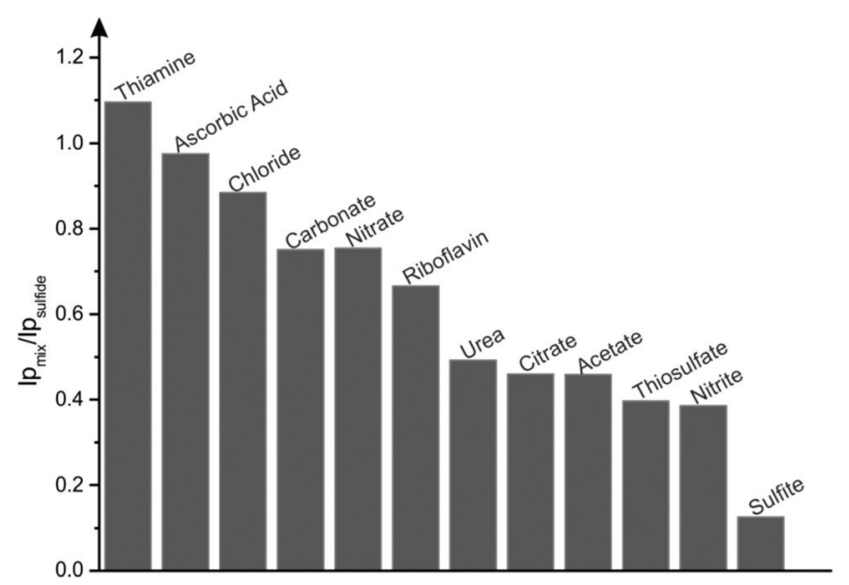

Fig. 3 LSV peak current ratio of sulfide $(2 \mathrm{mM})$ in the presence of coexistent interferents ([sulfide]: [interferents] 1:20) at CuSPE sensor. Note that concentration of riboflavin is $0.2 \mathrm{mM}$ as it is sparingly soluble in aqueous solutions.

Table 2 Results obtained from the analysis of sulfide in real tap water samples using CuSPEs $(N=3)$

\begin{tabular}{llllc}
\hline No. & $\begin{array}{l}\text { Spiked/ } \\
\mathrm{mM}\end{array}$ & $\begin{array}{l}\text { Recovered/ } \\
\mathrm{mM}\end{array}$ & \% RSD & $\begin{array}{l}\text { \% Apparent } \\
\text { recovery }\end{array}$ \\
\hline 1 & 0.15 & 0.15 & 1.65 & 99.4 \\
2 & 0.45 & 0.42 & 2.58 & 94.3 \\
3 & 0.65 & 0.66 & 2.22 & 102.1
\end{tabular}




\section{Conclusions}

This paper has reported for the first time the fabrication and application of nanocopper-oxide screen-printed electrodes for the mediatorless electrochemical sensing of sulfide in aqueous media. These robust and disposable sensing platforms produced in mass with a relatively low cost present a new genre of sulfide sensors wherein the sensitivity is competitive in comparison with other reported metallic-based electrochemical sensors which involve multiple fabrication steps. Quantification of sulfide by using fabricated CuSPE was also evaluated within the presence of a series of potential interferents such as nitrite, sulfite, citrate, acetate, urea and thiosulfate. Moreover, the CuSPEs exhibited acceptable recovery values for analysis of sulfide within a tap water sample marking their potential for use in different fields.

\section{Acknowledgements}

We acknowledge the support of the Analytical Chemistry Trust Fund of the Royal Society for a Developing World Scholarship Grant for BT and a British Council Institutional Link grant (no. 172726574). E. Bernalte acknowledges funding from Junta de Extremadura (Spain, PO 14021).

\section{References}

1 A. Stein and S. M. Bailey, Redox Biol., 2013, 1, 32-39.

2 D. Long Vu and L. Červenka, Electroanalysis, 2013, 25, 1967-1973.

3 M.-Y. Wu, K. Li, J.-T. Hou, Z. Huang and X.-Q. Yu, Org. Biomol. Chem., 2012, 10, 8342-8347.

4 F. Ma, M. Sun, K. Zhang, H. Yu, Z. Wang and S. Wang, Anal. Chim. Acta, 2015, 879, 104-110.

5 A. P. Ruas de Souza, C. W. Foster, A. V. Kolliopoulos, M. Bertotti and C. E. Banks, Analyst, 2015, 140, 4130-4136.

6 J. P. Smith, J. P. Metters, C. Irving, O. B. Sutcliffe and C. E. Banks, Analyst, 2014, 139, 389-400.

7 E. Bernalte, C. Marín Sánchez and E. Pinilla Gil, Electroanalysis, 2013, 25, 289-294.

8 S. K. Pandey, K. H. Kim and K. T. Tang, TrAC, Trends Anal. Chem., 2012, 32, 87-99.

9 J. Radford-Knoery and G. A. Cutter, Anal. Chem., 1993, 65, 976-982.

10 T. S. Bailey and M. D. Pluth, J. Am. Chem. Soc., 2013, 135, 16697-16704.

11 M. Colon, M. Iglesias, M. Hidalgo and J. L. Todoli, J. Anal. At. Spectrom., 2008, 23, 416-418.

12 N. S. Lawrence, J. Davis and R. G. Compton, Talanta, 2000, 52, 771-784.

13 M. Asad, M. H. Sheikhi, M. Pourfath and M. Moradi, Sens. Actuators, B, 2015, 210, 1-8.

14 M. Berahman and M. H. Sheikhi, Sens. Actuators, B, 2015, 219, 338-345.
15 D. W. H. Fam, A. I. Y. Tok, A. Palaniappan, P. Nopphawan, A. Lohani and S. G. Mhaisalkar, Sens. Actuators, B, 2009, 138, 189-192.

16 M. Zhao, X. Wang, L. Ning, J. Jia, X. Li and L. Cao, Sens. Actuators, B, 2011, 156, 588-592.

17 G. Schiavon, G. Zotti, R. Toniolo and G. Bontempelli, Anal. Chem., 1995, 67, 318-323.

18 D. Giovanelli, N. S. Lawrence, L. Jiang, T. G. J. Jones and R. G. Compton, Analyst, 2003, 128, 173-177.

19 E. Bitziou, M. B. Joseph, T. L. Read, N. Palmer, T. Mollart, M. E. Newton and J. V. Macpherson, Anal. Chem., 2014, 86, 10834-10840.

20 D. Giovanelli, N. S. Lawrence, L. Jiang, T. G. J. Jones and R. G. Compton, Sens. Actuators, B, 2003, 88, 320328.

21 M. Sun, H. Yu, H. Li, H. Xu, D. Huang and S. Wang, Inorg. Chem., 2015, 54, 3766-3772.

22 H. M. Chawla, P. Goel and P. Munjal, Tetrahedron Lett., 2015, 56, 682-685.

23 J. P. Metters, R. O. Kadara and C. E. Banks, Analyst, 2011, 136, 1067-1076.

24 J. P. Metters, D. K. Kampouris and C. E. Banks, Analyst, 2014, 139, 3999-4004.

25 T. Wang, E. P. Randviir and C. E. Banks, Analyst, 2014, 139, 2000-2003.

26 O. Ramdani, J. P. Metters, L. C. S. Figueiredo-Filho, O. Fatibello-Filho and C. E. Banks, Analyst, 2013, 138, 1053-1059.

27 J. Wang, B. Tian, V. B. Nascimento and L. Angnes, Electrochim. Acta, 1998, 43, 3459-3465.

28 S. Laschi, M. Fránek and M. Mascini, Electroanalysis, 2000, 12, 1293-1298.

29 L. Falciola, V. Pifferi and E. Mascheroni, Electroanalysis, 2012, 24, 767-775.

30 J. P. Smith, J. P. Metters, D. K. Kampouris, C. Lledo-Fernandez, O. B. Sutcliffe and C. E. Banks, Analyst, 2013, 138, 6185-6191.

31 J. M. Slater and J. W. Dilleen, Electroanalysis, 1997, 9, 13531359.

32 M. Regiart, L. A. Escudero, P. Aranda, N. A. Martinez, F. A. Bertolino and J. Raba, Talanta, 2015, 135, 138144.

33 J. M. Zen, C. T. Hsu, A. Senthil Kumar, H. J. Lyuu and K. Y. Lin, Analyst, 2004, 129, 841-845.

34 J. M. Zen, H. H. Chung and A. S. Kumar, Analyst, 2000, 125, 1633-1637.

35 P. Y. Chen, H. H. Yang, C. C. Huang, Y. H. Chen and Y. Shih, Electrochim. Acta, 2015, 161, 100-107.

36 N. A. Choudhry, D. K. Kampouris, R. O. Kadara, N. Jenkinson and C. E. Banks, Anal. Methods, 2009, 1, 183-187.

37 C. W. Foster, J. P. Metters, D. K. Kampouris and C. E. Banks, Electroanalysis, 2014, 26, 262-274.

38 C. W. Foster, J. P. Metters and C. E. Banks, Electroanalysis, 2013, 25, 2275-2282.

39 F. E. Galdino, C. W. Foster, J. A. Bonacin and C. E. Banks, Anal. Methods, 2015, 7, 1208-1214. 
40 P. M. Hallam, D. K. Kampouris, R. O. Kadara and C. E. Banks, Analyst, 2010, 135, 1947-1952.

41 R. O. Kadara, N. Jenkinson and C. E. Banks, Sens. Actuators, $B, 2009,138,556-562$.

42 M. Lamache and D. Bauer, Anal. Chem., 1979, 51, 1320-1322.

43 P. Velásquez, D. Leinen, J. Pascual, J. R. Ramos-Barrado, R. Cordova, H. Gómez and R. Schrebler, J. Electroanal. Chem., 2001, 510, 20-28.

44 I. Ciglenečki, D. Krznarić and G. R. Helz, Environ. Sci. Technol., 2005, 39, 7492-7498.
45 Y. Dilgin, B. Kızllkaya, B. Ertek, N. Eren and D. G. Dilgin, Talanta, 2012, 89, 490-495.

46 N. S. Lawrence, M. Thompson, C. Prado, L. Jiang, T. G. J. Jones and R. G. Compton, Electroanalysis, 2002, 14, 499-504.

47 D. Giovanelli, N. S. Lawrence, S. J. Wilkins, L. Jiang, T. G. J. Jones and R. G. Compton, Talanta, 2003, 61, 211220.

48 M. A. Aziz, M. Sohail, M. Oyama and W. Mahfoz, Electroanalysis, 2015, 27, 1268-1275. 